\title{
Influence of Glass and Sisal Fibers on the Cure Kinetics of Unsaturated Polyester Resin
}

\author{
Vinicius Pistor $^{\mathrm{a} *}$, Silvia Simone da Silva dos Santos Soares ${ }^{\mathrm{a}}$, Heitor Luiz Ornaghi Júnior ${ }^{\mathrm{a}, \mathrm{b}}$, \\ Rudinei Fiorio ${ }^{\text {, Ademir José Zattera }}{ }^{\text {a }}$
}

aLaboratory of Polymers, Universidade de Caxias do Sul - UCS, Rua Francisco Getúlio Vargas, 1130, CEP 95070-560, Caxias do Sul, RS, Brazil

${ }^{\mathrm{b}}$ Laboratory of Composite Materials, Program of Postgraduate Studies in Mining, Metals and Materials Engineering, Department of Materials Engineering, Federal University of Rio Grande do Sul - UFRGS, Av. Bento Gonçalves, 9500, CEP 91501-970, Porto Alegre, RS, Brazil

${ }^{c}$ Federal Institute of Education, Science and Techonology of Rio Grande do Sul - IFRS, Rua Mário de Boni, 2250, CEP 95012-580, Caxias do Sul, RS, Brazil

Received: September 12, 2011; Revised: May 9, 2012

\begin{abstract}
The effect of grinded glass and sisal fibers ( $25 \mathrm{vol} \%)$ on the cure kinetics of composites of unsaturated polyester resin (UPR) was investigated by differential scanning calorimetry (DSC) and scanning electron microscopy (SEM). The DSC analysis was carried out at four different heating rates $\left(5,10,20\right.$ and $\left.40^{\circ} \mathrm{C} / \mathrm{min}\right)$, and the cure enthalpy and activation energy $\left(E_{a}\right)$ were determined according to the Flynn-Wall-Ozawa (FWO) method. The results showed that increasing heating rates promoted reduced reaction times. The sisal fiber-containing composites exhibit higher activation energy values for the cure process in comparison with the neat polyester resin and the glass fiber composites. This can be due to the presence of polar groups in the sisal components, which physically interact with the polyester resin and retard the cure reaction. Hence, as sisal fiber retarded the cure reaction of the UPR resin, it is suggested that the use of natural fibers in polymer matrix composites can affect the cure kinetics of the polyester resin.
\end{abstract}

Keywords: composites, activation energy, FWO method and cure kinetics

\section{Introduction}

Over the past few decades, polymers have replaced many conventional materials due to benefits such as low density and easy processability. In particular, reinforced polymers have attracted the researchers attention due to their advantages over established materials. However, to obtain specific properties, polymer composites require to be modified by appropriate constituent materials; for example, fibers, whiskers and fillers ${ }^{1-3}$.

There are basically two types of fibers: natural and synthetic. Vegetal fibers are biodegradable, readily available from natural resources, cheap, of lower density and abrasive nature, and higher specific strength, among other features. Other desirable properties include high impact strength, high flexibility, less equipment abrasion, less skin and respiratory irritation, vibration damping and enhanced energy recovery ${ }^{1-4}$.

Furthermore, natural fibers contain a significant amount of hydroxyls and due to their high cellulose content their structure is around $70 \%$ crystalline, which characterizes relevant structural differences in comparison with, for example, glass fiber ${ }^{5}$. The differences cited in the literature must be considered for possible applications of natural fibers -based composites, as the contact surface between

*e-mail: pistorv@yahoo.com.br the matrix and discontinuous phase can directly influence the cure kinetics of the polymer matrix ${ }^{6}$.

Coir, sisal, jute, waste silk, cotton and bamboo are some natural fibers described in the literature ${ }^{4-6}$. Their composition consists mainly of cellulose fibrils embedded in a lignin matrix, the fibrils being aligned along the length of the fiber, their components including cellulose, hemicellulose, lignin, pectin, waxes and water ${ }^{7-10}$. The reinforcing efficiency of natural fibers is related to the nature and crystallinity of cellulose $\mathrm{e}^{7}$.

The literature reports that the sisal fiber density (1.33-1.45 g. $\mathrm{cm}^{-3}$ ) is lower than that of E-glass $\left(2.5-2.55 \mathrm{~g} . \mathrm{cm}^{-3}\right)^{11-13}$. The lower sisal fiber density offers the potential to provide higher added value, especially in the automotive industry, through the manufacturing of non-structural lightweight parts ${ }^{14}$.

In contrast, owing to poor moisture resistance, degradation in some properties of the natural fiber composites should be considered, causing a limitation of their use for some applications. Hybridization of natural fibers with synthetic fibers is one of the techniques adopted to overcome some of the drawbacks that have been identified, combining two fibers in a single matrix in order to compensate the disadvantages of one fiber in the presence of the other one. In order to improve the fiber-matrix interface the application 
of natural or synthetic fibers as reinforcements in composite materials requires strong adhesion between the fibers and the matrix. Physical and chemical treatments can be used to optimize this interface. To improve the mechanical properties of the final composite, a thin reactive coating (sizing), generally consisting of coupling agents, can be used to treat the fibers; this induces physical or chemical bonds between the matrix and the fibers ${ }^{15,16}$.

Kinetic studies are required in order to understand and optimize the manufacture of composites. Many isothermal $^{17-20}$ and non-isothermal ${ }^{21}$ models for thermal analysis have been used to determine the cure kinetics. Some non-isothermal models are based on analyses carried out at different heating rates () applied to the system studied ${ }^{22-24}$.

In an earlier study reported by Fei Yao et al. ${ }^{25}$, some models were employed for the evaluation of the decomposition kinetics in different fibers. The Kissinger, Friedman, Flynn-Wall-Ozawa and modified Coats-Redfern methods were used. For all fibers, approximately $60 \%$ of the thermal decomposition occurred in the temperature range of 215 and $310{ }^{\circ} \mathrm{C}$. For all methods, the activation energy $\left(E_{a}\right)$ showed a similar trend. The $E_{a}$ value obtained is the sum of the activation energy of all chemical reactions and physical processes that occur during the thermal degradation.

The aim of this study is to evaluate the cure kinetics of an unsaturated polyester resin (UPR), containing glass fiber (UPR/GF) and sisal fiber (UPR/SF) reinforcements.

\section{Materials}

Sisal fiber (SF) yarn was obtained from Sisalândia Fios Naturais (Bahia, Brazil). Glass fiber (GF) roving EC 2400 P207 was purchased from Vetrotex. Orthophthalic unsaturated polyester resin UC 2090 (Elekeiroz S.A., Brazil), containing octoate cobalt as catalyst, was used in this study. Methyl ethyl ketone peroxide (P-MEK, Disfibra Ltda., Brazil), was used as curing agent. $N$-butyl acetate (MERCK) was used to determine the densities of the composites.

\section{Methods}

\subsection{Fiber milling}

Fibers were milled in a Medizintechnik ball mill (model TMA-69022; Leipzig, Germany) aiming to increase the surface area by reduction the fiber size and improve the homogeneity and dispersion of the reinforcements in the polyester matrix. Ceramic spheres of 30 and $25 \mathrm{~mm}$ diameter, in quantities of 35 and 81 units, respectively, were used during the milling process. The sisal fiber was washed twice in distilled water and dried for 90 minutes at $105^{\circ} \mathrm{C}$.

\subsection{Granulometry analysis}

For the granulometry analysis of the grinded fibers, a Produtest shaker was used. The sieve sizes were $0.149 \mathrm{~mm}$, $0.074 \mathrm{~mm}$ and bottom. The granulometry analysis was carried out for 20 minutes.

\subsection{Sample preparation}

Sample preparation was carried out with 25 vol\% of glass or sisal fibers $(16.7 \mathrm{~mL}$ of fibers for $50 \mathrm{~mL}$ of polyester resin) and incorporated of 2 vol\% of P-MEK. The densities were determined according to ASTM D792 in $n$-butyl acetate.

\subsection{Scanning electron microscopy (SEM)}

Scanning electron microscopy (SEM) was carried out using a Superscan S-550 apparatus, with a secondary electron detector and acceleration voltage of $15.0 \mathrm{~kW}$. The scanning was carried out at magnifications of $2000 \times$ and $500 \times$. The samples were previously metalized with gold.

\subsection{Differential scanning calorimetry (DSC)}

The DSC measurements were recorded by a Shimadzu DSC50 apparatus under nitrogen atmosphere $(40 \mathrm{~mL} / \mathrm{min})$. Samples of $\approx 10 \mathrm{mg}$ for the polyester and $\approx 30 \mathrm{mg}$ for the composites were analyzed. Samples were heated from $25^{\circ} \mathrm{C}$ up to $250{ }^{\circ} \mathrm{C}$ at four different heating rates $(5,10,20$ and $\left.40{ }^{\circ} \mathrm{C} / \mathrm{min}\right)^{26-30}$.

\subsection{The Flynn-Wall-Ozawa (FWO) method}

The kinetic method proposed by Flynn, Wall ${ }^{27}$ and Ozawa $^{28}$ can estimate the activation energy of chemical reactions. The resolution of the FWO method can be attained by integral approximation, considering that FWO is an isoconversional method used to estimate the activation energy. The FWO method supports a Doyle's approximation $^{21,30}$ through which Equation 1 can be obtained:

$\log (\beta)=\log \left(\frac{A E_{a}}{R}\right)-\log (g(\alpha(T)))-2.315-0.4567 \frac{E_{a}}{R T}$

where $g((T))$ is related to the conversion.

\section{Results and Discussion}

The densities estimated for the neat resin, glass fiber and sisal fiber were $1.17,2.50$ and $1.10{\mathrm{~g} . \mathrm{cm}^{-3}}^{-}$, respectively.

The granulometry test results indicated particle sizes of $30 \pm 11 \mu \mathrm{m}$ for the grinded sisal fiber and $26 \pm 8 \mu \mathrm{m}$ for the grinded glass fiber. In addition, from the SEM analysis of the grinded glass fiber fiber-shaped particles (Figure 1a, b) can be observed; however, in general, the geometry evidenced was that of a refined powder. In contrast, for the grinded sisal fiber (Figure 1c, d), the fibrous aspect was not clearly identified.

\subsection{Differential Scanning Calorimetry (DSC)}

Figure 2 shows the DSC thermograms for the UPR obtained by applying different heating rates. Only the mass of resin was correlated to the heat released in the polymerization processes. As expected, an increasing heating rate promoted a faster reaction, leading to lower time required to complete total conversion. Similar behavior was observed for Figure 3 the composites.

Conversions $(\alpha)$ could be obtained by integrating the exothermic peak related to the cure reaction of the systems, using Equation 1. The total heat reaction values $\left(\Delta \mathrm{H}_{\text {tot }}\right)$ used to determine the conversions are presented in Table 1. 


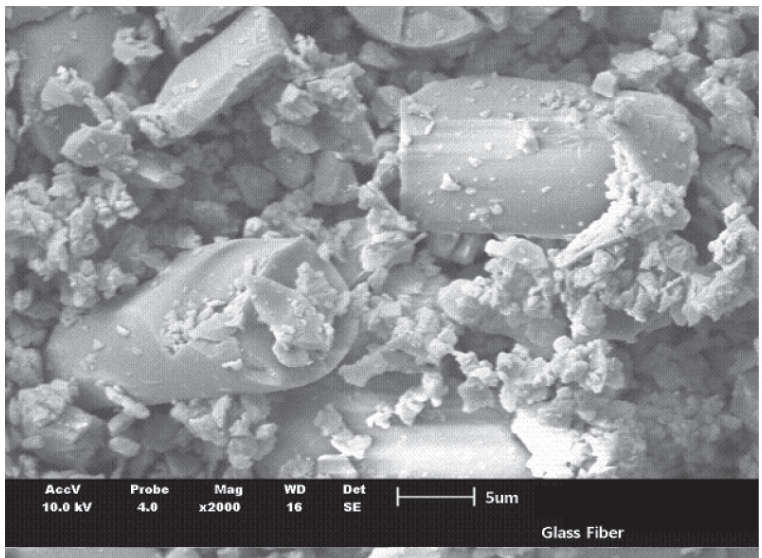

(a)

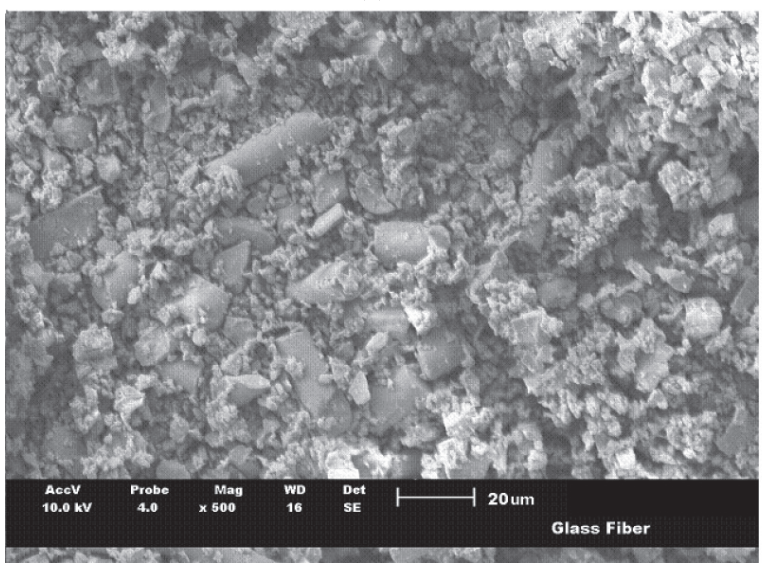

(c)

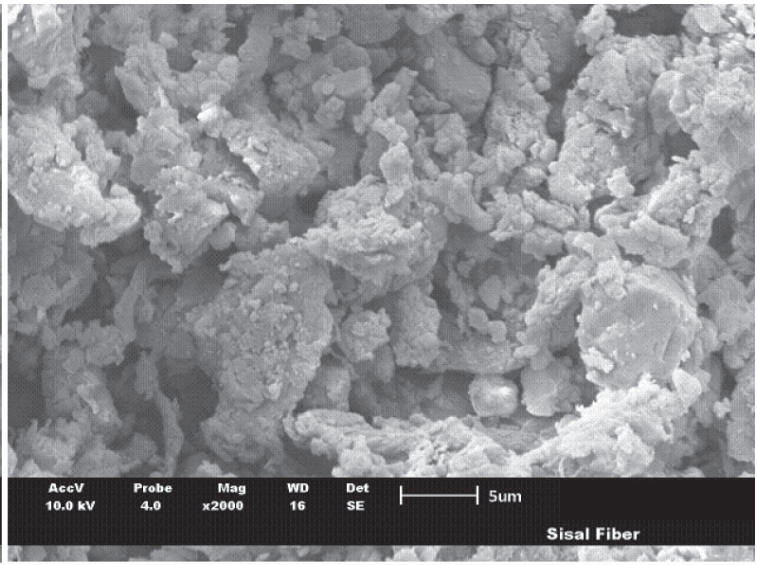

(b)

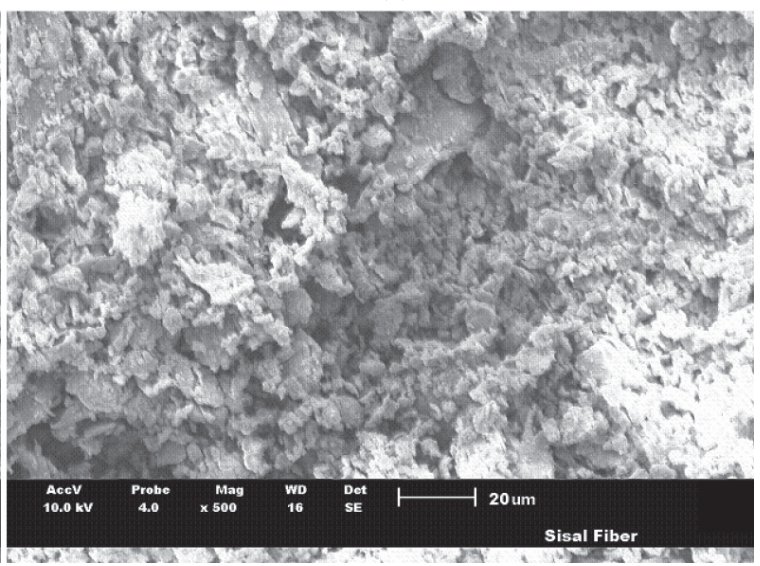

(d)

Figure 1. SEM images obtained for: glass fiber (a) $\times 2000$, (b) $\times 500$ and sisal fiber (c) $\times 2000$ and (d) $\times 500$.

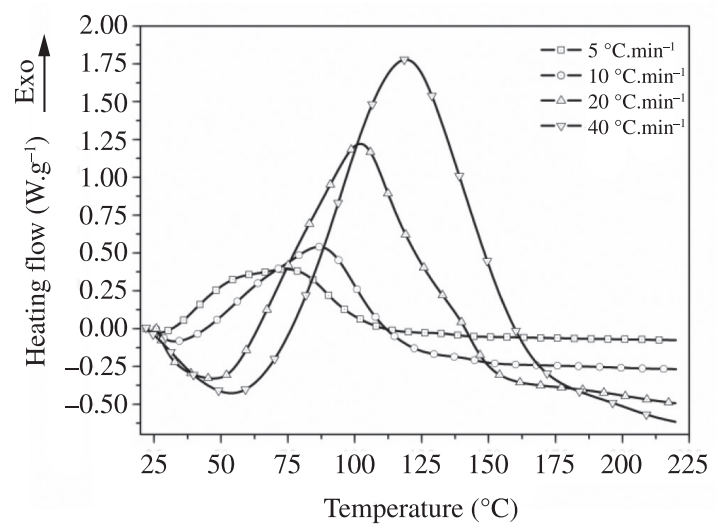

Figure 2. Thermograms obtained for different heating rates $(5,10$, 20 and $40{ }^{\circ} \mathrm{C} / \mathrm{min}$ ) for the UPR resin.

Table 1. Results obtained from the DSC thermograms.

\begin{tabular}{cccc}
\hline $\begin{array}{c}\beta\left({ }^{\circ} \mathbf{C} /\right. \\
\text { min })\end{array}$ & $\begin{array}{c}\mathbf{U P R} \mathbf{H}_{\text {tot }} \\
\left(\mathbf{J . g}^{-1}\right)\end{array}$ & $\begin{array}{c}\mathbf{U P R} / \mathbf{G F} \Delta \mathbf{H}_{\text {tot }} \\
\left(\mathbf{J J g}^{-1}\right)\end{array}$ & $\begin{array}{c}\mathbf{U P R} / \mathbf{S F} \Delta \mathbf{H}_{\text {tot }} \\
\left(\mathbf{J J g}^{-1}\right)\end{array}$ \\
\hline 5 & 277.5 & 275.0 & 213.9 \\
10 & 277.2 & 180.4 & 189.1 \\
20 & 257.9 & 179.5 & 188.5 \\
40 & 224.3 & 159.3 & 185.6 \\
\hline
\end{tabular}

According to Martín ${ }^{31}$, the heat generated in a cure reaction is independent of. The author states that when a low heating rate is used, the calorimetric signal is small; however, cure time is longer, and vice-versa; therefore $\mathrm{H}$ may be constant. However, the reduction in enthalpy with an increasing heating rate may be associated with shorter times required for the cure reaction to occur.

For isoconversional methods, the reaction rate in a fixed conversion is only temperature-dependent. Thus, using Equation 1, proposed by FWO, it is possible to obtain a plot of $\log v s .1 / \mathrm{T}$ for each conversion $(\alpha)$. Figure 4 shows the $\log$ vs. $1 / T$ plot for the unsaturated polyester resin, and the UPR/GF and UPR/SF systems showed similar behavior. The conversion values studied for all composites were set at between 0.02-0.8. The activation energies of the cure process for the systems were calculated from the slopes of the straight lines obtained ${ }^{26-28}$.

The activation energy values are shown in Table 2 . The results obtained for the $E$ of UPR showed two kinetic stages. Firstly, for $=0.02-0.2$, a decrease in $E_{a}$ was observed from 46.7 to $43.7 \mathrm{~kJ} \mathrm{~mol}^{-1}$. With the reaction advancement, the $E_{a}$ increased from 43.9 to $46.6 \mathrm{~kJ} \mathrm{~mol}^{-1}$ for $=0.3-0.6$. Stabilization of the activation energies in the range of

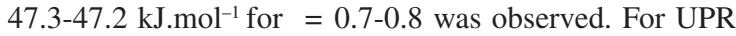
similar $E_{a}$ values were found in the literature ${ }^{32}$. The chemical 
Table 2. Activation energy $\left(E_{a}\right)$ and correlation coefficient $(r)$ values for the samples studied.

\begin{tabular}{|c|c|c|c|c|c|c|}
\hline \multicolumn{3}{|c|}{ Polyester resin (UPR) } & \multicolumn{2}{|c|}{ Polyester/Glass Fiber (UPR/GF) } & \multicolumn{2}{|c|}{ Polyester/Sisal Fiber (UPR/SF) } \\
\hline $\mathbf{a}_{\mathrm{p}}$ & $E_{a}\left(\mathbf{k J} . \mathrm{mol}^{-1}\right)$ & $r$ & $E_{a}\left(\mathbf{k J} . \mathrm{mol}^{-1}\right)$ & $r$ & $E_{a}\left(\mathbf{k J} \cdot \mathbf{m o l}^{-1}\right)$ & $r$ \\
\hline 0.02 & 46.7 & -0.996 & 50.6 & -0.998 & 86.9 & -0.993 \\
\hline 0.05 & 45.4 & -0.997 & 49.1 & -0.998 & 80.9 & -0.993 \\
\hline 0.1 & 44.5 & -0.997 & 47.9 & -0.998 & 77.8 & -0.993 \\
\hline 0.2 & 43.7 & -0.997 & 46.5 & -0.997 & 74.5 & -0.990 \\
\hline 0.3 & 43.9 & -0.997 & 45.9 & -0.998 & 73.2 & -0.980 \\
\hline 0.4 & 44.3 & -0.996 & 46.3 & -0.997 & 72.6 & -0.973 \\
\hline 0.5 & 45.5 & -0.996 & 47.4 & -0.997 & 73.0 & -0.966 \\
\hline 0.6 & 46.6 & -0.996 & 48.6 & -0.997 & 73.1 & -0.961 \\
\hline 0.7 & 47.3 & -0.995 & 49.3 & -0.997 & 73.7 & -0.960 \\
\hline 0.8 & 47.2 & -0.995 & 49.2 & -0.998 & 73.7 & -0.960 \\
\hline
\end{tabular}

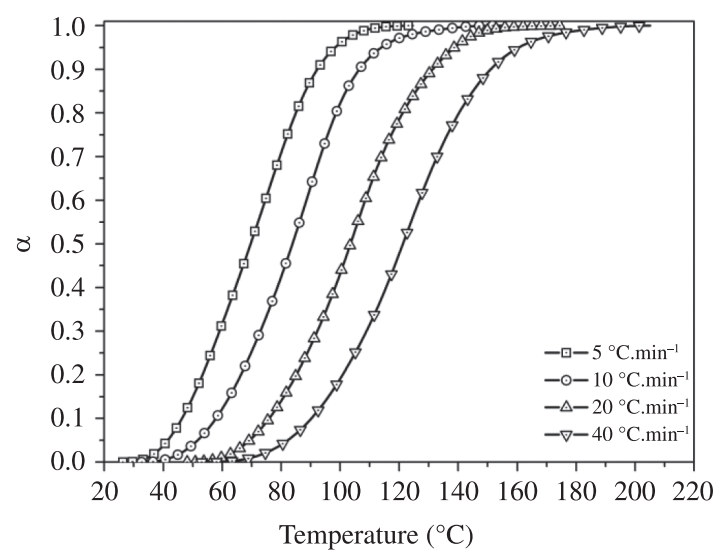

Figure 3. Conversion given by Equation 1 for the UPR resin.

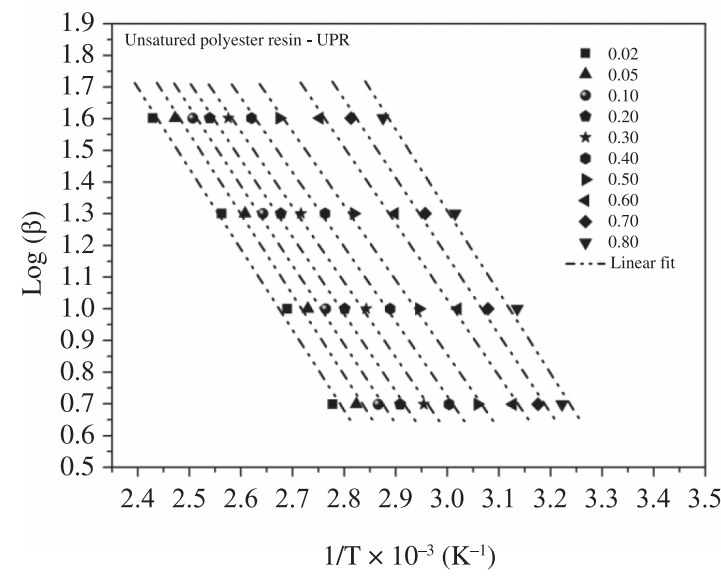

Figure 4. $\log$ vs. $1 / T$ for the determination of the activation energy of UPR resin.

reactions features for each stage have been widely discussed in literature ${ }^{33}$.

In a study of the UPR cure behavior by $\mathrm{Lu}$ and co-authors ${ }^{34}$ using the Avrami equation it was suggested that the beginning of cure is characterized by styrene polymerization through the formation of microgel structures that remain dispersed as monomers and oligomers. Also, as the polymerization occurs rapidly, it can be considered that the nucleation of the crosslinking network is probably instantaneous.

Yang and Lee ${ }^{35}$ also reported that the cure of UPR is followed by the formation of structural heterogeneities (microgel) resulting from intermolecular networks and, as a consequence, spherical structures are formed.

Table 2 and Figure 5 show the $E_{a}$ values for the neat resin, UPR/GF and UPR/SF composites. A decrease is observed in the activation energies values in the conversion range of 0.02 to 0.3 both for the neat polyester resin and the UPR/GF composite. For the UPR/SF composite, the decreasing range is between $=0.02-0.4$. After this, $E_{a}$ values increase for all samples studied. The initial reduction in $E_{a}$ is related both to an autocatalytic effect and the exothermic heat generated during the polymerization process. For the neat polyester resin the subsequent increase in $E_{a}$ for higher conversion values can be related to the formation of a microgel structure ${ }^{34,35}$. For the UPR/GF and UPR/SF composites, this behavior can be attributed to the formation of a microgel structure, as well as a restriction in the reaction due to the presence of a non-reactive phase.

Some authors state that the interface between the polymer matrix and glass fiber affects the cure reaction as well as the chemical composition and functionalized surface $^{36-39}$. Kalaprasad et al. ${ }^{40}$ describe the nature of a glass fiber as being isotropic and amorphous and, although the glass fiber has a thin reactive coating (sizing), this may explain the difference in the $E_{a}$ values for UPR/GF and $\mathrm{UPR}^{41}$.

The $E_{a}$ values for UPR/SF were found to be higher than those for neat UPR and the UPR/GF system. The $E_{a}$ values for $=0.02$ and 0.8 were 86.9 and $73.7 \mathrm{~kJ}$. $\mathrm{mol}^{-1}$, respectively. Sisal is composed of organic structures (cellulose, hemicellulose, lignin, etc.) and has a significant amount of hydroxyl groups ${ }^{5,42}$; these structures can interact with the resin, affecting the cure process.

Mwaikambo and Ansell ${ }^{5}$ studied the chemical modification of sisal and other fibers by alkalization and reported that all plant fibers are composed basically of cellulose, hemicellulose, lignin, wax and pectin, among others. Therefore, the chemical composition of fibers 


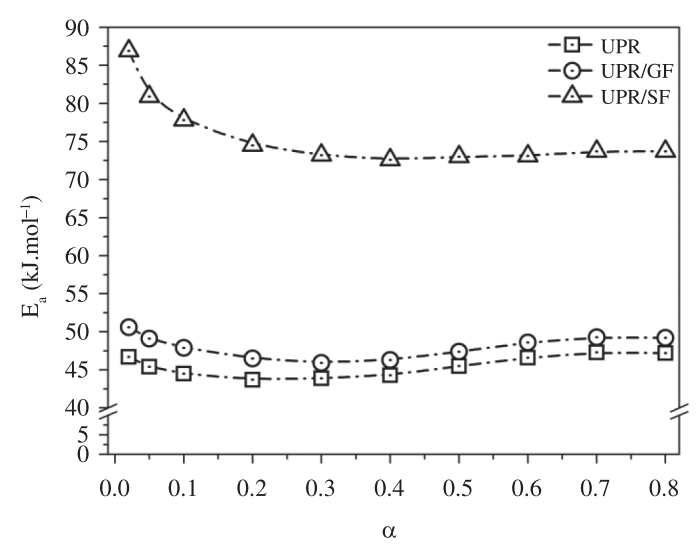

Figure 5. $E_{a}$ for UPR, UPR/GF and UPR/SF as a function of conversion.

affects their properties. Higher-lignin content plant fibers have better reactivity and as a result, are appropriate for use as chemical modifiers. On the other hand, highercellulose content fibers will have superior stiffness, being better employed in resin reinforcement. The structure of cellulose is semicrystalline and has hydroxyl groups; however, a high amount of cellulose is involved by substances like lignin ${ }^{5}$.

As a result of the polar and crystalline feature of SF, the cure reaction of UPR may be influenced by the interface between the phases of the system. Physical interactions, such as hydrogen bonding can occur, affecting kinetic parameters. The literature cites that the interface of polymer matrix composites with untreated sisal fibers is poorer when compared with the treated ones ${ }^{43}$.

\section{References}

1. MiY, Guo Q and Chen X. Bamboo fiber-reinforced polypropylene composites: A study of the mechaniacl properties. Journal of Applied Polymer Science. 1998; 69:1891-1899. http://dx.doi. org/10.1002/(SICI)1097-4628(19980906)69:10<1891::AIDAPP1>3.0.CO;2-9

2. Kuo PY, Wang SY, Chen JH, Hsueh HC and Tsai MJ. Effects of material compositions on the mechanical properties of wood-plastic composites manufactured by injection molding. Materials \& Design. 2009; 39:3489-3496. http://dx.doi. org/10.1016/j.matdes.2009.03.012

3. Patel VA and Parsania PH. Performance evaluation of alkali and acrylic acid treated-untreated jute composites of mixed epoxy-phenolic resins. Journal of Reinforced Plastics and Composites. 2010; 29:725-739. http://dx.doi. org/10.1177/0731684408100692

4. Sgriccia N, Hawley MC and Misra M. Characterization of natural fiber surfaces and natural fiber composites. Composites Part A: Applied Science and Manufacturing. 2008; 39:1632-1637. http://dx.doi.org/10.1016/j.compositesa.2008.07.007

5. Mwaikambo LY and Ansell MP. Chemical modification of hemp, sisal, jute, and kapok fibers by alkalization. Journal of Applied Polymer Science. 2002; 84:2222-2234. http://dx.doi. org/10.1002/app.10460
Polyester resins are of polar nature, so the removal of surface impurities on the plant fibers is advantageous in terms of fiber-matrix adhesion, assisting both mechanical interlocking and bonding reactions through exposure of the hydroxyl groups to chemicals. The removal of impurities provides not only more polar and reactive hydroxyl groups but also a rough surface, these features being obtained by physical and/or chemical modification ${ }^{5}$.

\section{Conclusions}

In this study, the influence of glass and sisal fibers on the thermal and cure kinetics of unsaturated polyester resin was investigated.

The DSC results showed that an increasing heating rates promoted a decrease in reaction time. The activation energy values of the cure process, obtained through the FWO method, showed that glass fiber-containing composites had higher activation energy values compared with the neat polyester resin, indicating that the size and surface area of the particles affect the cure kinetics of the composites. The sisal fiber-containing composites showed the highest activation energy values for the cure process, compared to the other systems studied herein.

Thus, the use of natural fibers in the polymer matrix composites can affect the cure kinetics of the thermoset resins, indicating that modifications in the parameters and processes may be necessary if these fibers are used as substitute materials for synthetic fibers.

\section{Acknowledgements}

The authors would like to thank UFRGS and UCS, and also CNPq, CAPES and FAPERGS for the financial support of this work.

6. Yousefi A, Lafleur PG and Gauvin R. Kinetic studies of thermoset cure reactions: a review. Polymer Composite. 1997; 18:157-168. http://dx.doi.org/10.1002/pc.10270

7. John MJ and Thomas S. Biofibres and biocomposites. Carbohydrate Polymers. 2008; 71:343-364. http://dx.doi. org/10.1016/j.carbpol.2007.05.040

8. Alsina OLS, De Carvalho LH, Ramos Filho FG and D'Almeida JRM. Thermal properties of hybrid lignocellulosic fabric-reinforced polyester matrix composites. Polymer Testing. 2005; 24:81-85. http://dx.doi.org/10.1016/j. polymertesting.2004.07.005

9. Yeng-Fong S. A study of the fiber obtained from the water bamboo husks. Bioresource Technology. 2007; 98:819-828. PMid:16759852. http://dx.doi.org/10.1016/j. biortech.2006.03.025

10. Satyanarayana KG, Guimarães JL and Wypych F. Studies on lignocellulosic fibers of Brazil. Part I: Source, production, morphology, properties and applications. Composites Part A: Applied Science and Manufacturing. 2007; 38:1694-1709. http://dx.doi.org/10.1016/j.compositesa.2007.02.006

11. Mishra S, Mohanty AK, Drzal LT, Misra M, Parija, Nayak SK et al. Studies on mechanical performance of biofibre/glass reinforced polyester hybrid composites. Composite Science \& 
Technology. 2003; 63:1377-1385. http://dx.doi.org/10.1016/ S0266-3538(03)00084-8

12. John V and Naidu VS. Tensile properties of unsaturated polyester-based sisal fiber-glass fiber hybrid composites. Journal of Reinforced Plastics and Composites. 2004; 23:1815-1819. http://dx.doi.org/10.1177/0731684404041147

13. Ornaghi Junior HL, Bolner AS, Fiorio R, Zattera AJ and Amico SC. Mechanical and dynamic mechanical analysis of hybrid composites molded by resin transfer molding. Journal of Applied Polymer Science. 2010; 118:887-896.

14. Zah R, Hischier R, Leão AL and Brown I. Curaua fibers in automobile industry - a sustainability assessment. Journal of Cleaner Production. 2007; 15:1032-1040. http://dx.doi. org/10.1016/j.jclepro.2006.05.036

15. Arun KV and Kamat RD, Basavarajappa S. Mechanism of translaminar fracture in glass/textile fabric polymer hybrid composites. Journal of Reinforced Plastics and Composites. 2010; 29:254-265. http://dx.doi. org/10.1177/0731684408097759

16. Marais S, Gouanvé F, Bonnesoeur A, Grenet J, Poncin-Epaillard F, Morvan C et al. Unsaturated polyester composites reinforced with flax fibers: effect of cold plasma and autoclave treatment on mechanical and permeation properties. Composites Part A: Applied Science and Manufacturing. 2005; 36:975-986. http:// dx.doi.org/10.1016/j.compositesa.2004.11.008

17. Ahmed KS, Vijayarangan S and Rajput C. Mechanical behavior of isoftalic polyester-based untreated woven jute and glass fabric hybrid composites. Journal of Reinforced Plastics and Composites. 2006; 25:1549-1569. http://dx.doi. org/10.1177/0731684406066747

18. Avrami M. Kinetics of phase change. I. General Theory. Journal of Chemistry Physics. 1939; 7:1103-1112. http:// dx.doi.org/10.1063/1.1750380

19. Avrami M. Kinetics of phase change. II. Transformation-time relations for random distribution of nuclei. Journal of Chemistry Physics. 1939; 8:212-224. http://dx.doi.org/10.1063/1.1750631

20. Avrami M. Kinetics of phase change. III. Granulation, phase change, and microstructure. Journal of Chemistry Physics. 1939; 9:177-184. http://dx.doi.org/10.1063/1.1750872

21. Zetterlund PB and Johnson AF. A new method for the determination of the Arrhenius constants for the cure process of unsaturated polyester resins based on a mechanism model. Thermochimica Acta. 1996; 289:209-221. http://dx.doi. org/10.1016/S0040-6031(96)03011-0

22. Hsiao KT, Little R, Restrepo O and Minaie B. A study of direct kinetics characterization during liquid composite molding. Composites Part A: Applied Science and Manufacturing. 2006; 37:925-933. http://dx.doi.org/10.1016/j. compositesa.2005.01.019

23. Pagano RL, Calado VMA, Tavares FW and Biscaia Junior EC. Cure kinetic parameter estimation of thermosetting resins with isothermal data by using particle swarm optimization. European Polymer Journal. 2008; 44:2678-2686. http://dx.doi. org/10.1016/j.eurpolymj.2008.05.017

24. Pistor V, Ornaghi FG, Fiorio R and Zattera AJ. Thermal characterization of oil extracted from ethylene-propylene-diene terpolymer residues (EPDM-r). Thermochimica Acta. 2010; 20:93-96. http://dx.doi.org/10.1016/j. tca.2010.06.028

25. Yao F, Wu Q, Lei Y, Guo W and Xu Y. Thermal decomposition kinetics of natural fibers: activation energy with dynamic thermogravimetric analysis. Polymer Degradation and Stabilility. 2008; 93:90-98. http://dx.doi.org/10.1016/j. polymdegradstab.2007.10.012
26. Bianchi O, Oliveira RVB, Fiorio R, Martins JN, Zattera AJ and Canto LB. Assessment of Avrami, Ozawa and Avrami-Ozawa equations for determiantion of EVA crosslinking kinetics from DSC measurements. Polymer Testing. 2008; 27:722-729. http:// dx.doi.org/10.1016/j.polymertesting.2008.05.003

27. Flynn JH and Wall LA. General treatment of the thermogravimetry of polymers. Journal Research of National Bureau and Standards. 1966; 70:487-523.

28. Ozawa T. A new method of quantitative differential thermal analysis. Bulletin of Chemical Society of Japan. 1966; 39:2071-2085. http://dx.doi.org/10.1246/ bcsj.39.2071

29. Yao F, Wu Q, Lei Y, Guo W and Xu Y. Thermal decomposition kinetics of natural fibers: activation energy with dynamic thermogravimetric analysis. Polymer Degradation and Stability. 2008; 93:90-98. http://dx.doi.org/10.1016/j. polymdegradstab.2007.10.012

30. Doyle CD. Series approximations to the equation of thermogravimetric data. Nature. 1965; 207:290-291. http:// dx.doi.org/10.1038/207290a0

31. Martín JL. Kinetic analysis if an asymmetrical DSC peak in the curing of an unsaturated polyester resin catalysed with MEKP and cobalt octoate. Polymer. 1999; 40:3451-3462. http://dx.doi. org/10.1016/S0032-3861(98)00556-4

32. Kosar V and Gomzi Z. In-depth analysis of the mathematical model of polyester thermosets curing. European Polymer Journal. 2004; 40:2793-2802. http://dx.doi.org/10.1016/j. eurpolymj.2004.07.027

33. Yousefi A, Lafleur PG and Gauvin R. Kinetic studies of thermoset cure reactions: a review. Polymer Composites. 1997; 18:157-168. http://dx.doi.org/10.1002/ pc. 10270

34. Lu MG, Shim MJ and Kim SW. Curing behavior of an unsaturated polyester system analyzed by Avrami equation. Thermochimica Acta. 1998; 323:37-42. http://dx.doi. org/10.1016/S0040-6031(98)00506-1

35. Yang YS and Lee LJ. Polymer Processing and Engineering. 1987; 5:327-332.

36. Pangelinan AB, McCullough RL and Kelley MJ. Analytic model for surface induced molecular weight segregation in thermoplastic composites. Journal of Polymer Science Part B: Polymer Physics. 1994; 32:2383-2394. http://dx.doi. org/10.1002/polb.1994.090321409

37. Pangelinan AB, McCullough RL and Kelley MJ. Attenuated total reflectance FTIR analysis of surface-induced molecular weight segregation. Composites Part A: Applied Science and Manufacturing. 1999; 30:67-74. http://dx.doi.org/10.1016/ S1359-835X(98)00120-1

38. Palmese GR and McCullough RL. Kinetic and thermodynamic considerations regarding interphase formation in thermosetting composite systems. Journal of Adhesion. 1994; 44:29-49. http:// dx.doi.org/10.1080/00218469408026615

39. Palmese GR and McCullough RL. Analytic models for the equilibrium behavior of binary mixtures in the presence of a solid surface. Composites Part A: Applied Science and Manufacturing. 1999; 30:3-10. http://dx.doi.org/10.1016/ S1359-835X(98)00121-3

40. Kalaprasad G, Pradeep P, Mathew G, Pavithran C and Thomas S. Thermal conductivity and thermal diffusivity analyses of low-density polyethylene composites reinforced with sisal, glass and intimately mixed sisal/glass fibres. Composites Science and Technology. 2000; 60:2967-2977. http://dx.doi. org/10.1016/S0266-3538(00)00162-7 
41. Gorowara RL, Kosik WE, McKnight SH and McCullough RL. Molecular characterization of glass fiber surface coatings for thermosetting polymer matrix/glass fiber composites. Composites Part A: Applied Science and Manufacturing. 2001; 31:323-329. http://dx.doi.org/10.1016/ S1359-835X(00)00112-3

42. Satyanarayana KG, Guimarães JL and Wypych F. Studies on lignocellulosic fibers of Brazil. Part I: Source, production, morphology, properties and applications. Composites Part A:
Applied Science and Manufacturing. 2007; 38:1694-1709. http://dx.doi.org/10.1016/j.compositesa.2007.02.006

43. Paiva JMF and Frollini E. Unmodified and modified surface sisal fibers as reinforcement of phenolic and lignophenolic matrices composites: thermal analyses of fibers and composites. Macromolecular Materials and Engineering. 2006; 291:405-417. http://dx.doi.org/10.1002/ mame.200500334 